\title{
Phylogenetic Analyses of a New Group of Denitrifiers Capable of Anaerobic Growth on Toluene and Description of Azoarcus tolulyticus sp. nov.
}

\author{
JIZHONG ZHOU, ${ }^{1,2}$ MARCOS R. FRIES, ${ }^{1,2}$ JOANNE C. CHEE-SANFORD, ${ }^{3}$ AND JAMES M. TIEDJE ${ }^{1,2,3 *}$ \\ Center For Microbial Ecology, ${ }^{1}$ Department of Crop and Soil Sciences, ${ }^{2}$ and Department of Microbiology, ${ }^{3}$ \\ Michigan State University, East Lansing, Michigan 48824-1325
}

\begin{abstract}
To understand the phylogeny and taxonomy of eight new toluene-degrading denitrifying isolates, we performed a 16S rRNA sequence analysis and a gas chromatographic analysis of their cellular fatty acids and examined some of their biochemical and physiological features. These isolates had 16S rRNA sequence signatures identical to those of members of the beta subclass of the Proteobacteria. The levels of similarity were as follows: 97.9 to $99.9 \%$ among the new isolates; 91.2 to $92.4 \%$ between the new isolates and Azoarcus sp. strain S5b2; 95.3 to $96.2 \%$ between the new isolates and Azoarcus sp. strain BH72; and 94.8 to $95.3 \%$ between the new isolates and Azoarcus indigens $\mathrm{VB32}^{\mathrm{T}}$ ( $\mathrm{T}=$ type strain). Phylogenetic trees constructed by using the distance matrix, maximum-parsimony, and maximum-likelihood methods showed that our eight denitrifying isolates form a phylogenetically coherent cluster which represents a sister lineage of the previously described Azoarcus species. Furthermore, the fatty acid profiles, the cell morphology, and several physiological and nutritional characteristics of the eight isolates and the previously described members of the genus Azoarcus were also similar. In contrast to the previously described members of the genus Azoarcus, the eight new isolates were capable of degrading toluene under denitrifying conditions. We concluded that these toluene-degrading denitrifiers are members of a new species of the novel nitrogen-fixing genus Azoarcus. We propose the name Azoarcus tolulyticus for these toluene-degrading denitrifying isolates and designate strain Tol-4 the type strain.
\end{abstract}

Benzene, toluene, ethylbenzene, and xylenes, compounds present in gasoline, are major environmental pollutants. Microbial decomposition of these compounds under aerobic conditions is well-known, but oxygen is often limited in zones of aquifers that are contaminated with benzene, toluene, ethylbenzene, and xylenes. Nitrate has been shown to stimulate the anaerobic degradation of some of these compounds in some soils and aquifers $(11,12,14,18)$, but little is known about the organisms responsible for this activity.

The following three toluene-degrading denitrifying strains have been described previously: Pseudomonas sp. strain K172 (22), Pseudomonas sp. strain T (6), and strain T1 (7). The phylogeny of these isolates has not been determined. Recently, we isolated eight new toluene-degrading denitrifiers from a variety of environments $(3,4,9)$. The results of studies of partial 16S rRNA gene sequences $(\sim 280 \mathrm{bp})$ of these organisms and some of their physiological and morphological characteristics suggested that they are probably members of, or very closely related to, the novel nitrogen-fixing bacterial genus Azoarcus $(4,9)$. More importantly, these new isolates exhibit nitrogenase activity $(4,9)$, which is a key feature of the genus Azoarcus (19). However, while the previously described members of the genus Azoarcus were reported to be nondenitrifiers (19), the new isolates are able to grow on toluene under strictly anaerobic, denitrifying conditions. The previously described Azoarcus isolates were isolated principally from the rhizosphere of Kallar grass in tropical and subtropical regions (19), whereas the eight new isolates were isolated from a variety of nonrhizosphere habitats. In order to determine the phylogenetic position of these toluene-degrading denitrifiers, we se-

* Corresponding author. Mailing address: Center for Microbial Ecology, Plant and Soil Science Building, Michigan State University, East Lansing, MI 48824-1325. Fax: (517) 353-2917. Electronic mail address: 21394jmt@msu.edu. quenced almost the entire $16 \mathrm{~S}$ rRNA gene of each isolate. In addition, we examined the cellular fatty acid compositions and some biochemical and physiological features of these organisms. Our results showed that our isolates are a closely related group that can be readily distinguished from the previously described Azoarcus strains. This led us to propose a new species in the genus Azoarcus.

\section{MATERIALS AND METHODS}

Organisms and growth conditions. Eight unique, facultatively anaerobic toluene degraders were isolated under denitrifying conditions from a variety of environments $(3,4,9)$. The geographic distribution and habitat characteristics of these isolates are listed in Table 1 . These isolates were grown aerobically at $30^{\circ} \mathrm{C}$ on modified R2A (M-R2A) medium as described previously (9).

Genomic bacterial DNA isolation. Total DNA of each bacterial isolate was obtained by using the method of Zhou (25), with modifications. Cells from $15 \mathrm{ml}$ of a late-exponential-phase culture were pelleted and suspended in $4 \mathrm{ml}$ of extraction buffer containing $100 \mathrm{mM}$ Tris- $\mathrm{HCl}(\mathrm{pH} 8.0), 50 \mathrm{mM}$ EDTA, $1.4 \mathrm{M}$ $\mathrm{NaCl}$, and $1 \%$ (wt/vol) CTAB (hexadecyltrimethylammonium bromide). Proteinase $K$ was added to a final concentration of $50 \mu \mathrm{g} / \mathrm{ml}$, and the sample was mixed vigorously; then $400 \mu \mathrm{l}$ of $20 \%$ (wt/vol) sodium dodecyl sulfate was added, and the sample was incubated at $65^{\circ} \mathrm{C}$ for $2 \mathrm{~h}$ with gentle inversion every 15 to $20 \mathrm{~min}$. The sample was purified once with $2 \mathrm{ml}$ of phenol and $2 \mathrm{ml}$ of chloroformisoamyl alcohol (24:1) and once with $4 \mathrm{ml}$ of chloroform and centrifuged at $12,000 \times g$ for $10 \mathrm{~min}$, and the DNA was precipitated from the aqueous phase with 0.6 volume of isopropanol. The precipitated DNA was spooled out, washed with cold $70 \%$ ethanol, dissolved in $500 \mu \mathrm{l}$ of sterile distilled water which contained $10 \mu \mathrm{g}$ of heat-treated RNase $\mathrm{A}$, and incubated for $2 \mathrm{~h}$ at $37^{\circ} \mathrm{C}$. The sample was then purified with an equal volume of chloroform. The DNA was precipitated from the aqueous phase with 0.1 volume of $3 \mathrm{M}$ sodium acetate and 2 volumes of $95 \%$ ethanol, washed with $70 \%$ ethanol, dissolved in an appropriate volume of $1 \times \mathrm{TE}$, and stored at $4^{\circ} \mathrm{C}$

PCR. The oligonucleotides used for amplifying 16S rRNA genes were the primer set consisting of fD1 and $\mathrm{rP1}$ as described by Weisburg et al. (23), with modifications of the linker sequences, which contain restriction sites for ClaI and SalI or BamHI and SpeI. The 5' and 3' primers were 5'-CCATCGATGTCGAC AGAGTTTGATCCTGGCTCAG- $3^{\prime}$ and $5^{\prime}$-GACTAGTGGATCCACGGTTA CCTTGTTACGACTT-3', respectively. The oligonucleotides were synthesized at the Macromolecular Structure, Sequencing and Synthesis Facility at Michigan State University.

All stock solutions used for PCR amplification were prepared and all procedures were performed with the precautions suggested by Kwok and Higuchi (15). 
TABLE 1. Sources of the strains used in this study

\begin{tabular}{lll}
\hline Strain & \multicolumn{1}{c}{ Habitat from which the strain was isolated } & \multicolumn{1}{c}{ Geographic origin } \\
\hline Tol-4 ${ }^{\mathrm{T}}$ & Petroleum-contaminated freshwater aquifer sediment, 24 to 25 m deep & Northern Michigan \\
Td-1 & Petroleum-contaminated soil & Western Washington \\
Td-2 & Petroleum-contaminated soil & Western Washington \\
Td-3 & Petroleum-contaminated marine sediments & Huntington Beach, Calif. \\
Td-15 & Home compost pile, primarily lawn clippings & Lansing, Michigan \\
Td-17 & Soil from industrial area & Jabaquara, Sao Paulo State, Brazil \\
Td-19 & Soil from a landfill & Cubatao, Sao Paulo State, Brazil \\
Td-21 & Noncontaminated organic (muck) soil & Clinton County, Michigan \\
\hline
\end{tabular}

Approximately 200 to $300 \mathrm{ng}$ of genomic DNA was added to a standard $100-\mu \mathrm{l}$ PCR mixture containing $1 \times$ Taq polymerase buffer (10 mM Tris-Cl, $1.5 \mathrm{mM}$ $\mathrm{MgCl}_{2}, 50 \mathrm{mM} \mathrm{KCl}$ [pH 8.0]), $2.5 \mathrm{U}$ of Taq polymerase (Promega, Madison, Wis.), $200 \mu \mathrm{mol}$ of each deoxynucleoside triphosphate, and $100 \mathrm{pmol}$ of each primer. The reaction conditions were as follows: denaturation at $92^{\circ} \mathrm{C}$ for $2 \mathrm{~min}$, 30 cycles consisting of $94^{\circ} \mathrm{C}$ for $15 \mathrm{~s}, 55^{\circ} \mathrm{C}$ for $30 \mathrm{~s}$, and $72^{\circ} \mathrm{C}$ for $2 \mathrm{~min}$, and one additional 6-min cycle for chain elongation. The samples were stored at $4^{\circ} \mathrm{C}$. Temperature cycling was performed with a programmable temperature cycler (GeneAmp PCR System 9600; Perkin Elmer Corp., Norwalk, Conn.).

Cloning. Amplified PCR products were precipitated with 0.1 volume of $3 \mathrm{M}$ sodium acetate and 2 volumes of $95 \%$ ethanol, washed with $70 \%$ ethanol, and dissolved in an appropriate volume of $1 \times \mathrm{TE}$. Approximately $1 \mu \mathrm{g}$ of the amplified PCR products was digested with $20 \mathrm{U}$ of $\mathrm{BamHI}$ for $24 \mathrm{~h}$, precipitated with $95 \%$ ethanol, and digested with $20 \mathrm{U}$ of $\mathrm{ClaI}$ for $24 \mathrm{~h}$. The doubly digested DNA was then purified by gel electrophoresis on a $1 \%$ low-temperature agarose gel. The gel band corresponding to a 16S rRNA gene fragment was excised, and the DNA was recovered with GELase (Epicentre Technologies, Madison, Wis.) by using the "fast protocol" described in the manufacturer's instructions.

PCR products were cloned by using standard methods (1). Briefly, the purified BamHI-ClaI-digested DNA was ligated to pBluescript SK+ (Stratagene, La Jolla, Calif.) by using T4 ligase (Boehringer Mannheim, Indianapolis, Ind.) with a ratio of plasmid vector to inserts of 1:10. The recombinant DNA was transformed into Escherichia coli $\mathrm{DH} \alpha 5 \mathrm{~F}^{\prime}$ competent cells by electroporation by using E. coli Pulser (Bio-Rad Laboratories, Hercules, Calif.). The positive clones were screened by blue-white selection and were confirmed by the fragment size of BamHI-ClaI-digested plasmid DNA.

Determination of nucleotide sequences. The template DNA was isolated from bacteria grown on Terrific broth (which contained [per liter] $12 \mathrm{~g}$ of Bacto Tryptone [Difco Laboratories, Detroit, Mich.], $24 \mathrm{~g}$ of Bacto Yeast extract [Difco], and $5 \mathrm{~g}$ of glycerol, as well as $17 \mathrm{mM} \mathrm{KH}_{2} \mathrm{PO}_{4}$ and $72 \mathrm{mM} \mathrm{K}_{2} \mathrm{HPO}_{4}$ ) by using a Wizard Minipreps DNA purification system (Promega) according to the manufacturer's instructions. DNA sequences were determined by automated fluorescent Taq cycle sequencing by using ABI Catalyst 800 and a model 373A sequencer (Applied Biosystems, Foster City, Calif.). The forward sequencing primers used in this study spanned the following $E$. coli $16 \mathrm{~S}$ rRNA gene positions: 342 to 357,519 to 533,787 to 802 , and 1099 to 1114 . The reverse primers spanned positions 357 to 342,529 to 515,802 to 787 , and 1115 to 1100 . In addition, M13 forward and reverse primers were used to determine the sequences of both ends of the cloned 16S rRNA gene.

Computer analysis. The sequences were assembled by using the gel-assembling programs in the Genetics Computer Group software package (5) and were aligned with the sequences in the Ribosomal Database Project database (16) on the basis of both primary- and secondary-structure information. The resulting alignment was edited for appropriate analyses by. using the SUBALIGN and GDE programs from the Ribosomal Database Project.

The evolutionary distances between strains were estimated by the method of Jukes and Cantor (13). The 16S rRNA gene sequences were compared by using the following three methods: unweighted pair group method of analysis (UPGMA), maximum parsimony, and maximum likelihood using the programs in PHYLIP 3.5 (8). For the UPGMA and maximum-parsimony methods we used a bootstrap procedure with 500 and 100 replicates. The SEOBOOT program was used to obtain confidence levels for the UPGMA and maximum parsimony analyses. For the maximum-likelihood analysis, the transition/transversion ratio used was 2.0 , and the jumble option was used.

Gas chromatography of cellular fatty acids. Bacterial isolates were precultured on M-R2A medium and streaked onto plates containing $0.3 \%$ (wt/vol) tryptic soy broth supplemented with $1.5 \%$ (wt/vol) Bacto Agar (Difco). The plates were incubated at $30^{\circ} \mathrm{C}$ for 72 to $96 \mathrm{~h}$. The cells used for gas chromatographic analysis were collected from at least three plates by scraping them with a sterile loop. Saponification, methylation, and extraction of fatty acids were performed by using a previously described procedure (20). Numerical comparisons of the fatty acid profiles were carried out by using the program for principalcomponent analysis in SYSTAT 5.0 (SYSTAT, Inc., Evanston, Ill.).

Physiological tests. Inocula for all of the physiological tests were obtained from cells grown aerobically on M-R2A medium at $30^{\circ} \mathrm{C}$ for 24 to $48 \mathrm{~h}$. Gram staining and tests for catalase and cytochrome $c$ oxidase activities and starch hydrolysis were carried out by using standard methods (21) with known strains as positive and negative controls. Other biochemical tests were performed by using a GN MicroPlate (BIOLOG, Hayward, Calif.) and an API NFT kit (bioMerieux, Montalieu Vercieu, France) according to the manufacturers' instructions. The preparations were incubated at $37^{\circ} \mathrm{C}$, and results were recorded at 24 and $120 \mathrm{~h}$ and at various times between 24 and $120 \mathrm{~h}$.

Additional tests for growth on substrates were performed by using aerobic BS medium (9) adjusted to $\mathrm{pH} 7$ and incubated at $30^{\circ} \mathrm{C}$. The inoculum for each test was prepared from cells grown on M-R2A broth, harvested by centrifugation, washed twice with sterile saline, and resuspended in sterile BS medium before they were inoculated into BS medium amended with the test substrate. Azoarcus indigens $\mathrm{VB} 32^{\mathrm{T}}(\mathrm{T}=$ type strain) and Azoarcus sp. strain $\mathrm{S} 5 \mathrm{~b} 2$ were also included in the tests for glucose, maltose, and mannose utilization. Growth was measured by determining the increase in optical density at $600 \mathrm{~nm}$, and data were recorded after 1 week of incubation. Strains were also tested for growth in M-R2A broth adjusted to $\mathrm{pH} 3,4,5,6,7,8$, and 9 and in M-R2A broth containing $0,0.5,1,2$, 5 , and $10 \% \mathrm{NaCl}$. The temperature range for growth was determined by culturing organisms in standard M-R2A broth ( $\mathrm{pH} 7$ ) at $4,15,25,30,37$, and $45^{\circ} \mathrm{C}$. Strains were also tested for growth on nutrient agar, tryptic soy agar (TSA), and semisolid, nitrogen-free, malate-containing medium (19). The growth of each strain on complex media was compared with the growth of the organism on standard M-R2A medium. All tests were done in duplicate.

Nucleotide sequence accession numbers. The GenBank nucleotide sequence accession numbers for our isolates are as follows: Azoarcus tolulyticus Tol $4^{\mathrm{T}}$, L33694; $A$. tolulyticus Td-1, L33687; A tolulyticus Td-2, L33691; $A$. tolulyticus Td-3, L33693; $A$. tolulyticus Td-15, L33688; $A$. tolulyticus Td-17, L33689; $A$. tolulyticus Td-19, L33690; and A. tolulyticus Td-21, L33692.

\section{RESULTS AND DISCUSSION}

Sequence data. Using automated fluorescence sequencing, we determined almost the entire 16S rRNA gene sequences $(1,457$ or $1,458 \mathrm{bp})$ for the eight new isolates; these sequences corresponded to positions 28 to 1491 on the $E$. coli $16 \mathrm{~S}$ rRNA gene. Although the isolates were obtained from a variety of environments (Table 1), their 16S rRNA genes showed that they were very closely related, with levels of similarity of 97.9 to $99.9 \%$ (Table 2). Three of these isolates, Tol- $4^{\mathbf{T}}$, Td-1, and Td-2, had sequences that were extremely similar (levels of similarity, 99.7 to $99.9 \%$ ) but not identical (Table 2). This finding was supported by the results of repetitive extragenic palindromic PCR analyses, which showed that the eight isolates had distinct repetitive extragenic palindromic PCR patterns (9). The $\mathrm{G}+\mathrm{C}$ contents of the $16 \mathrm{~S}$ rRNA genes of these isolates ranged from 56.1 to $56.6 \mathrm{~mol} \%$.

Phylogenetic analyses. An analysis of the helices between positions 180 and 220 of the $E$. coli $16 \mathrm{~S}$ rRNA gene sequence (24) indicated that the new isolates belong to the beta or gamma subdivision (data not shown). The signature sequences of these isolates matched the signature sequences of members of the beta subdivision of the Proteobacteria (24) (Table 3).

To further study the phylogenetic relationships of our isolates, their 16S rRNA gene sequences were compared with those of members of the beta subclass of the Proteobacteria obtained from the Ribosomal Database Project. Our isolates exhibited substantial levels of similarity to members of the novel nitrogen-fixing bacterial genus Azoarcus (12). The levels of similarity between our isolates and Azoarcus sp. strain S5b2 
TABLE 2. Pairwise levels of sequence identity and evolutionary distances between the toluene-denitrifying isolates and members of the beta subclass of the Proteobacteria, as well as E. coli as an outgroup

\begin{tabular}{|c|c|c|c|c|c|c|c|c|c|c|c|c|c|c|c|}
\hline \multirow[b]{2}{*}{ Strain or species } & \multicolumn{15}{|c|}{$\%$ Sequence identity or evolutionary distance $\left(10^{2}\right)^{a}$} \\
\hline & 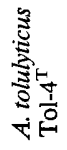 & 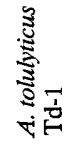 & 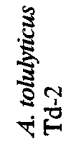 & 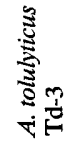 & 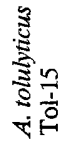 & 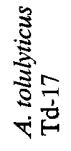 & 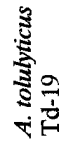 & 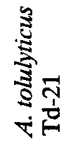 & 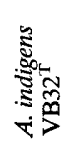 & 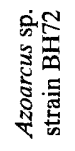 & 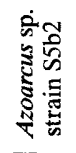 & 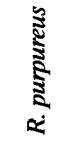 & 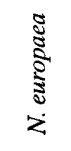 & 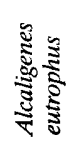 & $\begin{array}{l}: \widetilde{8} \\
\dot{8}\end{array}$ \\
\hline A. tolulyticus Tol-4 ${ }^{\mathbf{T}}$ & & 99.9 & 99.7 & 98.3 & 98.8 & 98.4 & 98.1 & 98.2 & 95.3 & 96.1 & 92.4 & 89.6 & 88.3 & 89.6 & 82.1 \\
\hline A. tolulyticus Td-1 & 0.1 & & 99.7 & 98.3 & 98.8 & 98.4 & 98.1 & 98.2 & 95.3 & 96.2 & 92.4 & 89.6 & 88.3 & 89.6 & 82.1 \\
\hline A. tolulyticus Td-3 & 1.7 & 1.7 & 1.7 & & 98.9 & 98.5 & 99.0 & 98.8 & 95.1 & 95.8 & 91.5 & 89.7 & 88.6 & 89.0 & 81.7 \\
\hline A. tolulyticus Td-15 & 1.3 & 1.3 & 1.5 & 1.0 & & 99.4 & 98.9 & 99.0 & 95.1 & 95.8 & 92.0 & 89.5 & 88.4 & 89.4 & 81.9 \\
\hline A. tolulyticus Td-17 & 1.6 & 1.6 & 1.8 & 1.5 & 0.6 & & 98.4 & 99.0 & 94.9 & 95.7 & 91.8 & 89.4 & 88.2 & 89.5 & 81.7 \\
\hline A. tolulyticus Td-19 & 2.0 & 2.0 & 2.1 & 1.0 & 1.1 & 1.6 & & 98.8 & 94.9 & 95.3 & 91.2 & 89.3 & 88.2 & 88.8 & 81.4 \\
\hline A. tolulyticus Td-21 & 1.9 & 1.9 & 2.0 & 1.1 & 1.0 & 1.0 & 1.3 & & 94.8 & 95.3 & 91.4 & 89.4 & 88.1 & 89.0 & 81.3 \\
\hline A. indigens $\mathrm{VB}^{2} 2^{\mathrm{T}}$ & 4.6 & 4.6 & 4.8 & 4.8 & 4.9 & 5.0 & 5.1 & 5.2 & & 97.5 & 93.5 & 90.9 & 88.3 & 89.7 & 83.0 \\
\hline Azoarcus sp. strain $\mathrm{BH} 72$ & 3.7 & 3.7 & 4.0 & 4.1 & 4.1 & 4.3 & 4.7 & 4.7 & 2.6 & & 93.4 & 90.9 & 88.9 & 90.2 & 82.2 \\
\hline Azoarcus sp. strain S5b2 & 7.9 & 7.9 & 8.2 & 8.9 & 8.3 & 8.5 & 9.3 & 9.0 & 6.8 & 7.0 & & 92.0 & 88.5 & 90.0 & 82.7 \\
\hline N. europaea & 12.4 & 12.4 & 12.6 & 12.0 & 12.4 & 12.6 & 12.6 & 12.8 & 12.8 & 12.2 & 12.5 & 13.0 & & 88.7 & 80.5 \\
\hline Alcaligenes eutrophus & 10.5 & 10.5 & 10.8 & 11.1 & 10.7 & 10.6 & 11.5 & 11.2 & 10.6 & 10.2 & 10.2 & 11.0 & 11.8 & & 81.2 \\
\hline E. coli & 20.4 & 20.4 & 20.7 & 20.9 & 20.7 & 20.9 & 21.4 & 21.5 & 19.3 & 20.6 & 20.0 & 21.2 & 22.4 & 21.4 & \\
\hline
\end{tabular}

${ }^{a}$ The values on the upper right are levels of sequence identity, and the values on the lower left are evolutionary distances.

were 91.2 to $92.4 \%$, the levels of similarity between our isolates and Azoarcus sp. strain BH72 were 95.3 to $96.2 \%$, and the levels of similarity between our isolates and $A$. indigens $\mathrm{VB} 32^{\mathrm{T}}$ were 94.8 to $95.3 \%$ (Table 2). More distantly related were the photosynthetic bacterium Rhodocyclus purpureus, the ammonia-oxidizing bacterium Nitrosomonas europaea, and Alcaligenes eutrophus (Table 2). The nearest known phylogenetic relative other than a member of the genus Azoarcus appeared to be the newly described selenate-respiring species Thauera selenatis (17), whose 16S rRNA sequence was $93 \%$ similar to the $16 \mathrm{~S}$ rRNA sequences of our strains. While $T$. selenatis does denitrify, it does not fix nitrogen.

In $100 \%$ of the UPGMA analyses, all eight toluene-degrading denitrifying isolates appeared in one cluster, which formed a sister lineage of the previously described Azoarcus species. Tol- $4^{\mathrm{T}}$, Td-1, and Td-2 formed a cluster that was separate from the other five isolates. The branches leading to Td-3, Td-15,

TABLE 3. Results of a signature sequence analysis performed with the eight new toluene-degrading denitrifying isolates and other taxa ${ }^{a}$

\begin{tabular}{lcccc}
\hline & \multicolumn{4}{c}{ Signature base $^{c}$} \\
\cline { 2 - 5 } Position $^{b}$ & Consensus & $\begin{array}{c}\text { A. } \\
\text { tolulyticus }\end{array}$ & $\begin{array}{c}\text { Beta } \\
\text { Proteobacteria }\end{array}$ & $\begin{array}{c}\text { Other } \\
\text { Proteobacteria }\end{array}$ \\
\hline 50 & $\mathrm{~A}$ & $\mathrm{U}$ & $\mathrm{U}$ & $\mathrm{A}$ \\
108 & $\mathrm{G} / \mathrm{C}$ & $\mathrm{A}$ & $\mathrm{A}$ & $\mathrm{G} / \mathrm{C}$ \\
640 & $\mathrm{~A}$ & $\mathrm{U}$ & $\mathrm{U} / \mathrm{G}$ & $\mathrm{A}$ \\
690 & $\mathrm{G}$ & $\mathrm{A}$ & $\mathrm{A}$ & $\mathrm{G}$ \\
722 & $\mathrm{G}$ & $\mathrm{A}$ & $\mathrm{A}$ & $\mathrm{G}$ \\
812 & $\mathrm{G}$ & $\mathrm{C}$ & $\mathrm{C}$ & $\mathrm{G}$ \\
871 & $\mathrm{U}$ & $\mathrm{G}$ & $\mathrm{G}$ & $\mathrm{U}$ \\
929 & $\mathrm{G}$ & $\mathrm{A}$ & $\mathrm{A}$ & $\mathrm{G}$ \\
947 & $\mathrm{G}$ & $\mathrm{U}$ & $\mathrm{U}$ & $\mathrm{G}$ \\
976 & $\mathrm{G}$ & $\mathrm{A}$ & $\mathrm{A} / \mathrm{g}$ & $\mathrm{G}$ \\
1234 & $\mathrm{C}$ & $\mathrm{A}$ & $\mathrm{A}$ & $\mathrm{C}$ \\
\hline
\end{tabular}

${ }^{a}$ Signature sequences were obtained from reference 24 .

${ }^{b}$ Standard $E$. coli $16 \mathrm{~S}$ rRNA numbering.

${ }^{c}$ A capital letter indicates a major base which accounts for $>90 \%$ of assayable cases. A lowercase letter indicates a minor base which is found in $<15 \%$ of the assayable cases or in only one sequence in the group (24).
Td-17, Td-19, and Td-21 had lower confidence levels, ranging from 56 to $82 \%$ (data not shown).

Our parsimony analysis yielded 12 equally most-parsimonious trees that differed only in the relative positions of Td-3, Td-15, Td-17, Td-19, and Td-21 and in the placement of $N$. europaea and Alcaligenes eutrophus. We also analyzed the data by using 100 replicates. The tree obtained (Fig. 1) provided confidence intervals for the nodes. The results shown in Fig. 1 are consistent with those based on our previous partial sequence analyses $(4,9)$.

The maximum-likelihood analysis yielded a topology (Fig. 2) that differed from the topology of the parsimony tree only in the position of $N$. europaea relative to Alcaligenes eutrophus and in the position of Azoarcus sp. strain $\mathrm{BH} 72$ relative to $A$. indigens $\mathrm{VB}^{\mathrm{T}}{ }^{\mathrm{T}}$. The maximum-likelihood dendrogram was

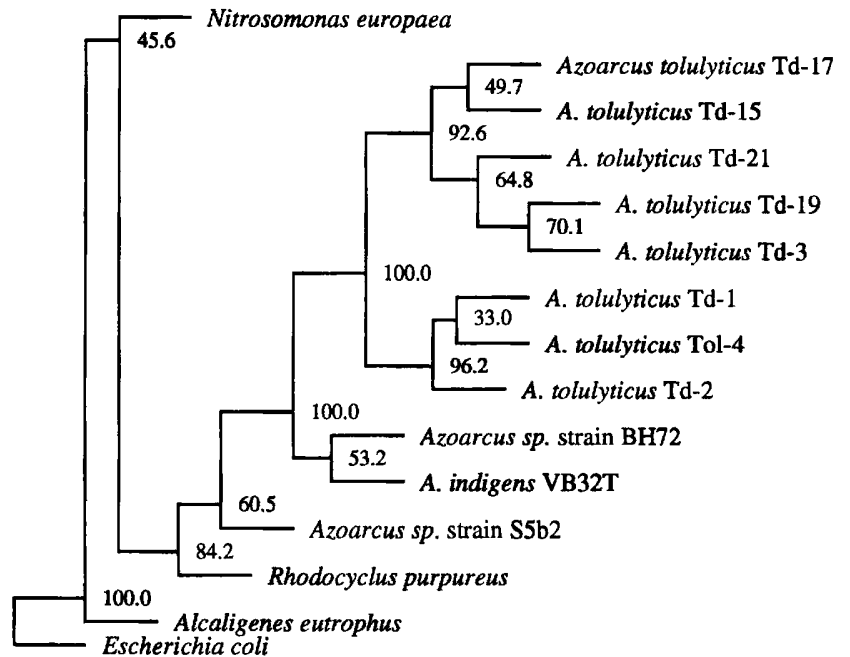

FIG. 1. Bootstrap parsimony tree obtained by using DNAPAR and SEQ BOOT with different $\boldsymbol{A}$. tolulyticus strains and related species. The percentages indicate the bootstrap confidence estimates on the branches obtained with 100 replicates. 


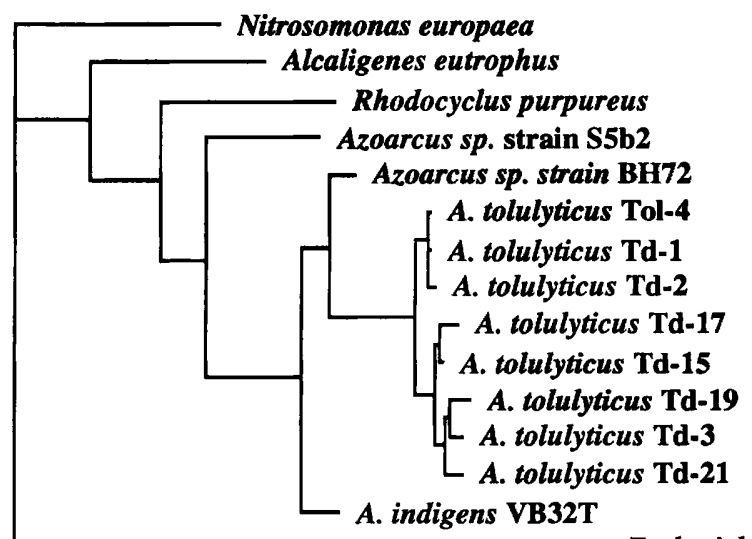

Escherichia coli

FIG. 2. Maximum-likelihood topology for different $A$. tolulyticus strains and related bacteria as determined by the jumble option based on 10 orderings of the data ( $\log$ likelihood, -5971$)$. The relative distances between nodes and tips and between internodes are shown. All branch lengths are significant at the $P=0.01$ level.

also very similar to the UPGMA dendrogram. Use of the jumble option yielded several different solutions with similar likelihood scores. These solutions always supported the following conclusions: (i) the eight isolates formed a phylogenetically coherent unit that was a sister lineage of Azoarcus species, which was also a sister lineage of $R$. purpureus; and (ii) the new isolates were more closely related to Azoarcus sp. strain $\mathrm{BH} 72$ and $A$. indigens than to Azoarcus sp. strain S5b2.

The results of all three methods of analysis suggested that the eight toluene-degrading denitrifying isolates which we studied were (i) phylogenetically very closely related to each other and (ii) members of the genus Azoarcus.

Cellular fatty acid methyl ester patterns. The major fatty acids of all of the new isolates were 16:0, cis-7 16:1, 3-OH 10:0, 12:0, and 18:1 fatty acids (Table 4), but we observed a number of variations in the minor fatty acids present in the isolates. For example, Td-15 lacked 15:0, cyclo 17:0, and 18:0 fatty acids, and Td-17 did not contain 10:0, 15:0, and 18:0 fatty acids. Td-2, Td-3, and Td-21 contained small amounts of 19:0, 3-OH 17:0, and 19:1 fatty acids, respectively. The absence or presence of small amounts of some fatty acids could be regarded as characteristics of different isolates. None of the fatty acid patterns of our isolates matched the fatty acid patterns in the MIDI

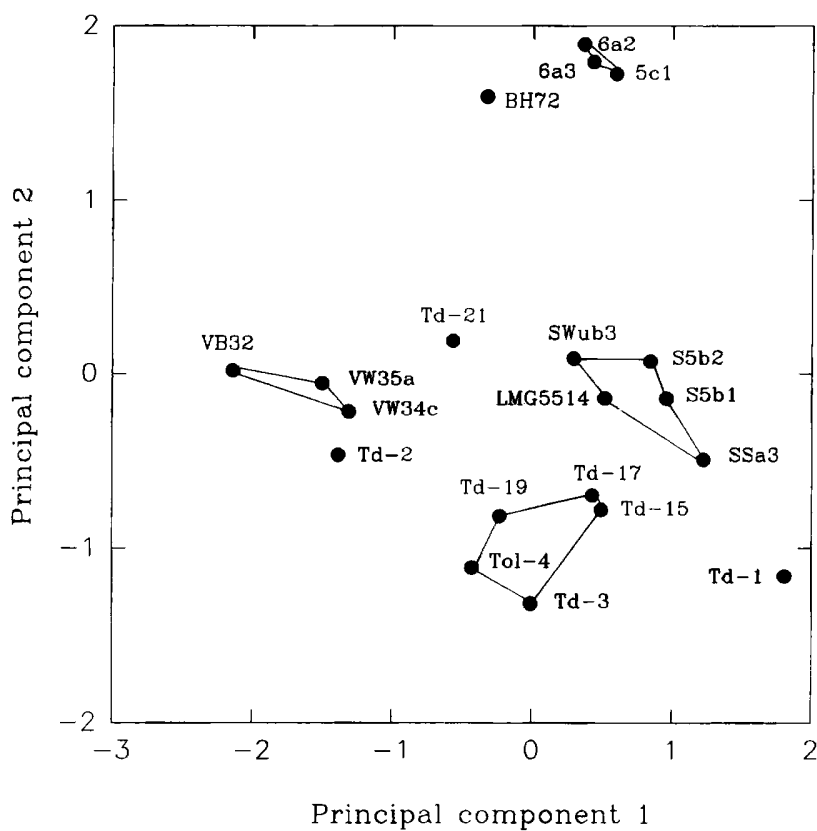

FIG. 3. Two-dimensional plot obtained from a principal-component analysis of the cellular fatty acid profiles of the eight toluene-degrading denitrifiers, as well as 12 other Azoarcus strains. The previously described strains of the genus Azoarcus formed three clusters, as recognized by Reinhold-Hurek et al. (19). Most of the new isolates appeared to belong to a new cluster.

database. There were no fatty acid profiles of Azoarcus sp. strains in the MIDI database.

The fatty acid profiles of the eight isolates which we studied were very similar to those of previously described members of the genus Azoarcus (19). 16:0 and cis-7 16:1 fatty acids were predominant in both the previously described and new isolates. In contrast to the previously described members of the genus Azoarcus, however, all eight new isolates contained a considerable amount of 12:0 fatty acid but lacked 3-OH 8:0 fatty acid. A numerical comparison of the profiles of the 16:0, cis-7 16:1, and 18:1 fatty acids of the eight new isolates and the previously described members of the genus Azoarcus revealed four clusters (Fig. 3). While the previously described members of the genus Azoarcus were in three clusters (19), five of our eight isolates (all of the isolates except Td-1, Td-2, and Td-21) ap-

TABLE 4. Cellular fatty acid compositions of the eight toluene-degrading denitrifying isolates

\begin{tabular}{|c|c|c|c|c|c|c|c|c|c|c|c|c|c|}
\hline \multirow[b]{2}{*}{ Strain } & \multicolumn{13}{|c|}{$\%$ of total fatty acids } \\
\hline & $10: 0^{a}$ & 3-OH 10:0 & $12: 0$ & $14: 0$ & $15: 0$ & $\begin{array}{l}c i s-7 \\
16: 1\end{array}$ & $16: 0$ & $\begin{array}{c}\text { cyclo } \\
17: 0\end{array}$ & $18: 1^{b}$ & $18: 0$ & 19:0 & $\begin{array}{c}3-\mathrm{OH} \\
17: 0\end{array}$ & 19:1 \\
\hline A. tolulyticus Tol-4 ${ }^{\mathbf{T}}$ & 0.53 & 7.74 & 9.49 & 1.54 & 0.49 & 44.67 & 30.95 & 1.21 & 2.63 & 0.50 & $\mathrm{ND}^{c}$ & ND & ND \\
\hline A. tolulyticus $\mathrm{Td}-1$ & 0.42 & 1.72 & 6.75 & 1.30 & 0.73 & 61.89 & 21.54 & 2.21 & 3.45 & ND & ND & ND & ND \\
\hline A. tolulyticus Td-2 & 0.64 & 5.52 & 12.8 & 0.90 & 0.61 & 44.01 & 23.41 & 4.11 & 7.02 & ND & 1.00 & ND & ND \\
\hline A. tolulyticus Td-3 & 0.56 & 4.91 & 12.8 & 2.13 & 0.51 & 50.29 & 25.11 & 0.80 & 2.22 & ND & ND & 0.80 & ND \\
\hline A. tolulyticus Td-15 & 0.47 & 6.24 & 7.28 & 0.95 & ND & 49.69 & 30.62 & ND & 4.42 & ND & ND & ND & ND \\
\hline A. tolulyticus Td-17 & ND & 4.91 & 4.89 & 1.55 & ND & 44.7 & 38.61 & 1.45 & 3.90 & ND & ND & ND & ND \\
\hline A. tolulyticus Td-19 & 0.38 & 5.93 & 7.93 & 1.23 & 0.86 & 42.79 & 35.95 & 0.90 & 3.60 & 0.44 & ND & ND & ND \\
\hline A. tolulyticus Td-21 & 0.36 & 4.02 & 4.34 & 1.18 & 0.87 & 42.33 & 33.59 & 1.19 & 9.31 & 0.28 & ND & ND & 0.45 \\
\hline
\end{tabular}

${ }^{a}$ Number of carbon atoms:number of unsaturated carbon bonds. cis refers to the configuration of the double bond, and the position is indicated relative to the aliphatic ends of the molecule; cyclo and $\mathrm{OH}$ indicate cyclopropane and hydroxyl substitutions, respectively.

Mixture of $7 \mathrm{c} / 9 \omega / 12 \omega, 9 \mathrm{c} / 12 \omega / 7 \mathrm{c}$, and $12 \omega / 9 \omega / 7 \mathrm{c}$.

${ }^{c} \mathrm{ND}$, not detected. 
TABLE 5. Characteristics of the eight toluene-degrading denitrifying isolates

\begin{tabular}{|c|c|c|c|c|c|c|c|c|}
\hline \multirow{2}{*}{ Test } & \multicolumn{8}{|c|}{ Strain } \\
\hline & Tol- $4^{\mathrm{T}}$ & Td-1 & Td-2 & Td-3 & Td-15 & Td-17 & Td-19 & Td-21 \\
\hline Gram stain & $-{ }^{a}$ & - & - & - & - & - & - & - \\
\hline Catalase & + & + & + & + & + & + & + & + \\
\hline Oxidase & + & + & + & + & + & + & + & + \\
\hline Nitrogen fixation & + & + & + & + & + & + & + & + \\
\hline Denitrification $^{b}$ & + & + & + & + & + & + & + & + \\
\hline Growth on nutrient agar & + & + & + & + & + & + & + & + \\
\hline Growth on TSA & $+w$ & $+w$ & $+w$ & $+w$ & $+\mathrm{w}$ & $+w$ & $+w$ & $+w$ \\
\hline Growth on $\mathrm{SM}^{c}$ & $+w$ & $+w$ & $+w$ & $+w$ & $+\mathrm{w}$ & $+\mathrm{w}$ & $+w$ & $+w$ \\
\hline Growth at $\mathrm{pH} 5^{d}$ & - & - & - & - & - & - & - & + \\
\hline $\begin{array}{l}\text { Growth in the presence } \\
\text { of } 2 \% \mathrm{NaCl}^{d}\end{array}$ & - & + & + & + & + & + & + & + \\
\hline Growth at $15^{\circ} \mathrm{C}^{d}$ & + & + & + & + & + & + & + & $+w$ \\
\hline Growth at $45^{\circ} \mathrm{C}^{d}$ & - & + & + & + & + & + & - & - \\
\hline \multicolumn{9}{|l|}{ Substrate utilization tests $e^{e}$} \\
\hline Glucose & + & + & + & + & $+w$ & $+\mathrm{w}$ & + & + \\
\hline Maltose & + & + & + & + & + & $+w$ & + & $+w$ \\
\hline Mannose & - & - & - & - & - & - & - & - \\
\hline Malate & + & + & + & + & + & - & + & - \\
\hline Ethanol & + & + & $+w$ & + & + & + & + & $+w$ \\
\hline Acetate & + & + & + & + & + & - & + & - \\
\hline Succinate & + & + & + & + & + & $+w$ & + & - \\
\hline Lactate & + & + & + & $+w$ & + & + & + & - \\
\hline Pyruvate & $+w$ & $+w$ & - & - & $+w$ & - & + & - \\
\hline Benzoate & + & + & + & + & + & + & + & $+w$ \\
\hline \multicolumn{9}{|l|}{ API NFT tests $f$} \\
\hline $\mathrm{NO}_{2}^{-}$ & - & - & $+v$ & - & - & - & - & - \\
\hline $\mathrm{N}_{2}$ & $+\mathrm{v}$ & + & + & + & - & + & + & + \\
\hline Glucose & + & $+\mathrm{v}$ & $-g$ & $+v$ & + & $-^{h}$ & + & - \\
\hline Maltose & + & + & + & + & + & - & + & $--^{i}$ \\
\hline Adipate & + & + & + & - & - & - & - & $--^{i}$ \\
\hline Malate & + & + & + & + & + & + & + & + \\
\hline Phenylacetate & - & - & - & - & - & + & - & - \\
\hline
\end{tabular}

a - , negative; + , positive; $+w$, weak growth; $+v$, variable (one of the duplicate tests was positive)

${ }^{b}$ Denitrification was determined by examining gas production by standard methods $(4,9)$.

$c$ SM, semisolid, nitrogen-free, malate-containing medium.

${ }^{d}$ Strains were tested in M-R2A broth adjusted to the appropriate $\mathrm{pH}$ or $\mathrm{NaCl}$ concentration. Standard $\mathrm{M}$-R2A medium was used to test for growth at different temperatures. All strains grew at $\mathrm{pH} 6$ to 9 , in the presence of $0,0.5$, and $1 \% \mathrm{NaCl}$, and at 25,30 , and $37^{\circ} \mathrm{C}$. None of the strains grew at pH 3 or 4 , in the presence of 5 or $10 \% \mathrm{NaCl}$, or at $4^{\circ} \mathrm{C}$.

${ }^{e}$ Aerobic growth on different substrates in BS medium after 1 week of incubation at $30^{\circ} \mathrm{C}$. Glucose, maltose, mannose, malate, and benzoate were tested at a concentration of $1 \mathrm{mM}$; ethanol, succinate, and lactate were tested at a concentration of $3 \mathrm{mM}$; and acetate and pyruvate were tested at a concentration of $5 \mathrm{mM}$.

${ }^{f}$ Data were recorded after $48 \mathrm{~h}$ of incubation. Duplicate tests were performed. $\mathrm{NO}_{2}{ }^{-}$and $\mathrm{N}_{2}$ were the products tested for in the nitrate reduction assay. None of the isolates grew on L-arabinose, D-mannose, D-mannitol, $N$-acetyl-D-glucosamine, D-gluconate, caprate, or citrate after $48 \mathrm{~h}$ of incubation. Td-21 was positive for utilization of mannitol and gluconate after $120 \mathrm{~h}$ of incubation. No strain fermented glucose. No tryptophanase, arginine dihydrolase, urease, esculin hydrolysis, gelatinase, and $\beta$-galactosidase activities were observed after incubation for $48 \mathrm{~h}$. Strains Tol-4 ${ }^{\mathrm{T}}$, Td- 1 , and Td-19 were positive for esculin hydrolysis after incubation for $72 \mathrm{~h}$. Strains Td-2, Td-3, Td-17, and Td-21 were positive for esculin hydrolysis after incubation for $120 \mathrm{~h}$. Strains Td-17 and Td-21 were positive for gelatinase activity after incubation for 72 and $96 \mathrm{~h}$, respectively.

$g$ Positive after incubation for $72 \mathrm{~h}$.

${ }^{h}$ Positive after incubation for $96 \mathrm{~h}$

${ }^{i}$ Positive after incubation for $120 \mathrm{~h}$.

peared to form a new cluster that was separated from the previously described members of the genus Azoarcus.

Physiological and biochemical analysis. All of the new isolates are gram negative, cytochrome $c$ oxidase positive, and catalase positive (Table 5). We previously showed that all of these isolates are capable of fixing nitrogen by growing on $\mathrm{N}_{2}$ (9). Most of the isolates exhibited esculin hydrolysis activity after $48 \mathrm{~h}$ (Table 5). No $\beta$-galactosidase, tryptophanase, urease, and arginine dihydrolase activities were observed. All of the isolates except Td-15 produced $\mathrm{N}_{2}$ gas in the $\mathrm{NO}_{3}{ }^{-}$reduction assay when the reagents supplied by an API NFT kit were used (Table 5). Td-15, as well as the other new strains, did produce $\mathrm{N}_{2}$ gas from nitrate when a more specific and sensitive assay was used to test for denitrification $(4,9)$. The difference in $\mathrm{N}_{2}$ production obtained in the two tests for denitrification with $\mathrm{Td}-15$ was probably due to differences in the compositions of the test media.

All of the isolates grew well on M-R2A medium and nutrient agar and poorly on TSA and semisolid, nitrogen-free, malatecontaining medium compared with growth on M-R2A medium (Table 5). All of the strains grew at $\mathrm{pH} 6$ to 9 , in the presence of $0,0.5$, and $1 \% \mathrm{NaCl}$, and at 25,30 , and $37^{\circ} \mathrm{C}$. Some of the strains grew under conditions outside the ranges described above, but none grew at a $\mathrm{pH}$ of 4 or less or in the presence of an $\mathrm{NaCl}$ concentration of $5 \%$ or more. Although the results obtained for growth on glucose and maltose differed depending on the substrate assay used (Table 5), all or most of the isolates grew on glucose, maltose, malate, ethanol, acetate, succinate, and benzoate. The API NFT data obtained after the recommended $48 \mathrm{~h}$ of incubation are reported below, but pos- 
itive results for growth were obtained with several substrates after longer incubation periods. No starch hydrolysis or glucose fermentation was detected. The substrate oxidation profiles obtained by using BIOLOG GN MicroPlates were negative for each isolate after $24 \mathrm{~h}$ of incubation, and only after $120 \mathrm{~h}$ did some of the isolates show a positive or weak response to some carbon substrates (data not shown).

The substrate use patterns, particularly the substrate use patterns for organic acids, obtained with our isolates were similar to the patterns obtained with the previously described members of the genus Azoarcus (19). The new isolates, however, grew on glucose and maltose, while the previously described members of the genus Azoarcus reportedly do not grow on carbohydrates (19). Indeed, when $A$. indigens $\mathrm{VB}^{\mathrm{T}}{ }^{\mathrm{T}}$ and Azoarcus sp. strain S5b2 were assayed under our conditions, they did not grow on glucose, maltose, or mannose, while our strains grew on glucose and maltose. On the basis of the results of API NFT tests, the substrate range for the new isolates is limited, although this limitation may be due to the conditions under which they were tested. Also, in contrast to the previously described Azoarcus strains, the eight new isolates grew poorly on TSA. M-R2A medium and nutrient agar are solid media that support good growth of the new Azoarcus isolates. In addition, two of the previously described isolates $(A$. indigens VB32 ${ }^{\mathrm{T}}$ and Azoarcus sp. strain S5b2) did not degrade toluene under denitrifying conditions (unpublished data).

The morphology of isolates Td-1, Td-2, Td-3, Td-15, Td-17, Td-19, and Td-21 was described by Fries et al. (9), and the morphology of strain Tol- $4^{\mathrm{T}}$ was similar (4). The cells are short, motile rods (length, 1.4 to $2.1 \mu \mathrm{m}$ ) when the organisms are grown anaerobically on toluene; the cells are longer motile rods (length, 2.1 to $2.8 \mu \mathrm{m}$ ) or occur in long chains when the organisms are grown on M-R2A agar. Growth on M-R2A medium resulted in uniform, translucent yellowish colonies that were approximately 2 to $3 \mathrm{~mm}$ in diameter and had dark centers. The cellular morphology of the new isolates is similar to the cellular morphology of the previously described Azoarcus species (19). Additional details concerning characterization of type strain Tol- 4 and its anaerobic metabolism of toluene have been determined by Chee-Sanford et al. (4).

The ability to fix nitrogen, the fatty acid methyl ester profiles, and the physiological, biochemical, and morphological features strongly support the conclusion based on the results of $16 \mathrm{~S}$ rRNA sequence analyses that the new isolates are members of the nitrogen-fixing bacterial genus Azoarcus. However, the toluene-degrading ability of these organisms under denitrifying conditions, their nonrhizosphere niche, several physiological, biochemical, and nutritional differences, and differences of 3 to $8 \%$ between their 16S rRNA sequences and the 16S rRNA sequences of other Azoarcus species suggest that the new isolates are members of a new species in the genus Azoarcus. Hence, we formally propose that these toluene-degrading denitrifiers should be placed in a new species of the genus Azoarcus. Since toluene-degrading ability under denitrifying conditions is the key feature that differentiates these isolates from the previously described members of the genus Azoarcus, we propose the name Azoarcus tolulyticus for them.

Description of Azoarcus tolulyticus sp. nov. Azoarcus tolulyticus (to.lu.ly'ti.cus. N. L. n. Fr. Sp. tolu, balsam from Santiago de Tolu, toluene; Gr. adj. lyticus, dissolving; N. L. masc. adj. tolulyticus, toluene dissolving). Cells are gram-negative, short, motile rods (length, 1.4 to $2.1 \mu \mathrm{m}$ ) when the organisms are grown anaerobically on toluene; cells are longer motile rods (length, 2.1 to $2.8 \mu \mathrm{m}$ ) or occur in long chains when the organisms are grown on M-R2A agar. Growth on M-R2A medium results in uniform translucent yellowish colonies that are approximately 2 to $3 \mathrm{~mm}$ in diameter and have dark centers. Oxidase and catalase positive. Cells lack tryptophanase, $\beta$-galactosidase, urease, and arginine dihydrolase activities. Nitrate and oxygen can serve as terminal electron acceptors. Capable of growth on nitrogen-free media under a nitrogen $\left(\mathrm{N}_{2}\right)$ atmosphere. Grows well on M-R2A medium, nutrient agar, a few aromatic substrates, including toluene, and organic acids such as malate. Grows poorly on TSA. Limited substrate range. All strains grow at $\mathrm{pH} 6$ to 9 , in the presence of up to $1 \% \mathrm{NaCl}$, and at 25 to $37^{\circ} \mathrm{C}$. All strains have cis-7 16:1 and 16:0 fatty acids as their predominant cellular fatty acids. This organism belongs to the beta subclass of the Proteobacteria as determined by $16 \mathrm{~S}$ rRNA gene sequence analyses. In contrast to the previously described species of the genus Azoarcus, the strains are able to degrade toluene under denitrifying conditions, grow on glucose and maltose, contain a considerable amount of 12:0 fatty acid, and lack 3-OH 8:0 fatty acid.

Strain Tol-4, the type strain, has been deposited in The American Type Culture Collection as strain ATCC 51758. This strain was isolated from a petroleum-contaminated core taken from the Bear Lake aquifer in Northern Michigan.

\section{ACKNOWLEDGMENTS}

We are grateful to James R. Cole for supplying some of the sequencing primers, to Barbara Reinhold-Hurek for strains VB32 ${ }^{\top}$ and $S 5 b 2$, and to Emily Alexander for technical assistance.

This project was supported by National Institute of Environmental Health Sciences Superfund Research and Education grant ES-04911, and we used facilities provided to the Center for Microbial Ecology by National Science Foundation grant BIR9120006.

\section{REFERENCES}

1. Ausubel, F. M., R. Brent, R. E. Kingston, D. D. Moore, J. G. Seidman, J. A. Smith, and K. Struhl. 1990. Current protocols in molecular biology, vol. 2. Wiley Interscience, New York.

2. Brosius, J., T. J. Dull, D. D. Sleeter, and H. F. Noller. 1981. Gene organization and primary structure of a ribosomal RNA operon from Escherichia coli. J. Mol. Biol. 148:107-127.

3. Chee-Sanford, J., M. R. Fries, and J. M. Tiedje. 1992. Anaerobic degradation of toluene under denitrifying conditions in bacterial isolate Tol-4, abst. Q233, p. 374. In Abstracts of the 92nd General Meeting of the American Society for Microbiology 1992. American Society for Microbiology, Washington, D.C.

4. Chee-Sanford, J., M. R. Fries, J.-Z. Zhou, J. W. Frost, and J. M. Tiedje. Unpublished data.

5. Devereaux, J., P. Haeberli, and O. Smithies. 1984. A comprehensive set of sequence analysis programs for the VAX. Nucleic Acids Res. 12:387-395.

6. Dolfing, J., J. Zeyer, P. Binder-Eicher, and R. P. Schwarzenbach. 1990. Isolation and characterization of a bacterium that mineralizes toluene in the absence of molecular oxygen. Arch. Microbiol. 154:336-341.

7. Evans, P. J., D. T. Mang, K. S. Kim, and L. Y. Young. 1991. Anaerobic degradation of toluene by a denitrifying bacterium. Appl. Environ. Microbiol. 57:1139-1145.

8. Felsenstein, J. 1989. PHYLIP-phylogeny inference package (version 3.2). Cladistics 5:164-166.

9. Fries, M. R., J.-Z. Zhou, J. Chee-Sanford, and J. M. Tiedje. 1994. Isolation, characterization, and distribution of denitrifying toluene degraders from a variety of habitats. Appl. Environ. Microbiol. 60:2802-2810.

10. Hurek, T., S. Burggraf, C. R. Woese, and B. Reinhold-Hurek. 1993. $16 \mathrm{~S}$ rRNA-targeted polymerase chain reaction and oligonucleotide hybridization to screen for Azoarcus sp., grass-associated diazotrophs. Appl. Environ. Microbiol. 59:3816-3824.

11. Hutchins, S. R. 1991. Biodegradation of monoaromatic hydrocarbons by aquifer microorganisms using oxygen, nitrate, or nitrous oxide as the terminal electron acceptor. Appl. Environ. Microbiol. 57:2403-2407.

12. Hutchins, S. R., G. W. Sewell, D. A. Kovacs, and G. A. Smith. 1991. Biodegradation of aromatic hydrocarbons by aquifer microorganisms under denitrifying conditions. Environ. Sci. Technol. 25:68-76.

13. Jukes, T. H., and C. R. Cantor. 1969. Evolution of protein molecules, p. 21-132. In H. N. Munro (ed.), Mammalian protein metabolism. Academic Press, New York.

14. Kuhn, E. P., J. Zeyer, P. Eicher, and R. P. Schwarzenbach. 1988. Anaerobic degradation of alkylated benzenes in denitrifying laboratory columns. Appl. Environ. Microbiol. 54:490-496. 
15. Kwok, S., and R. Higuchi. 1989. Avoiding positives with PCR. Nature (London) 339:237-238

16. Larsen, N., G. J. Olsen, B. L. Maidak, M. J. McCaughey, R. Overbeek, T. J. Macke, T. L. Marsh, and C. R. Woese. 1993. The Ribosomal Database Project. Nucleic Acids Res. 21(Suppl.):3021-3023.

17. Macy, J. M., S. Reck, G. Auling, M. Dorsch, E. Stackebrandt, and L. I. Sly. 1993. Thauera selenatis gen. nov., sp. nov., a member of the beta subclass of Proteobacteria with a novel type of anaerobic respiration. Int. J. Syst. Bacteriol. 43:135-142.

18. Major, D. W., C. I. Mayfield, and J. F. Barker. 1988. Biotransformation of benzene by denitrification in aquifer sand. Ground Water 26:8-14.

19. Reinhold-Hurek, B., T. Hurek, M. Gillis, B. Hoste, M. Vancanneyt, K. Kersters, and J. De Ley. 1993. Azoarcus gen. nov., nitrogen-fixing Proteobacteria associated with roots of Kallar grass (Leptochloa fusca (L.) Kunth), and description of two species, Azoarcus indigens sp. nov. and Azoarcus communis sp. nov. Int. J. Syst. Bacteriol. 43:574-584.
20. Sasser, M. 1990 . Technical note 101: identification of bacteria by gas chromatography of cellular fatty acids. MIDI, Inc., North Newark, Del.

21. Smibert, R. M., and N. R. Krieg. 1981. General characterization, p. 409-443. In P. Gerhardt, R. G. E. Murray, R. N. Costilow, E. W. Nester, W. A. Wood, N. R. Krieg, and G. B. Phillips (ed.), Manual of methods for general bacteriology. American Society for Microbiology, Washington, D.C.

22. Tschech, A., and G. Fuchs. 1987. Anaerobic degradation of phenol by pure cultures of newly isolated denitrifying pseudomonads. Arch. Microbiol. 148: 213-217.

23. Weisburg, W. W., S. M. Barns, D. A. Pelletier, and D. J. Lane. 1991. 16S ribosomal DNA amplification for phylogenetic study. J. Bacteriol. 173:697703 .

24. Woese, C. R. 1987. Bacterial evolution. Microbiol. Rev. 51:221-271.

25. Zhou, J.-Z. 1993. Molecular evolution of nitrate reductase genes. Ph.D. dissertation. Washington State University, Pullman. 